\title{
IMPROVED COMPRESSIVE STRENGTH OF ALKALI ACTIVATED SLAG UPON
}

\section{HEATING}

\author{
Irena Nikolić ${ }^{*}$, Ljiljana Karanović ${ }^{2}$, Ivona Janković - Častvan ${ }^{3}$, Vuk Radmilović ${ }^{4}$, Slavko Mentus ${ }^{5}$, Velimir \\ Radmilović ${ }^{3}$ \\ ${ }^{1}$ University of Montenegro, Faculty of Metallurgy and Technology, DžordžaVašingtona bb, \\ 81000 Podgorica, Montenegro \\ ${ }^{2}$ University of Belgrade, Faculty of Mining and Geology, Laboratory of Crystallography, \\ Đušina 7, 11000 Belgrade, Serbia \\ ${ }^{3}$ University of Belgrade, Faculty of Technology and Metallurgy, Karnegijeva 4, \\ 11120 Belgrade, Serbia \\ ${ }^{4}$ Innovation center, University of Belgrade, Faculty of Technology and Metallurgy, Karnegijeva 4, \\ 11120 Belgrade, Serbia \\ ${ }^{5}$ University of Belgrade, Faculty of Physical Chemistry, Belgrade, Serbia
}

\begin{abstract}
This paper presents a study on thermal stability of alkali activated slag (AAS) prepared from electric arc furnace slag (EAFS) using a mixture of alkaline sodium hydroxide and sodium silicate solutions. The samples were investigated by means of XRD, SEM, TG/DTA and porosity analysis. Compressive strengths of AAS samples before and after exposure to elevated temperatures ranging from $600{ }^{\circ} \mathrm{C}$ to $1000{ }^{\circ} \mathrm{C}$ were determined. The significant microstructural modifications highlighted by changes in porosity due to the sintering process are responsible for the strengthening of AAS sample after heating at 600,800 and $1000{ }^{\circ} \mathrm{C}$. Moreover, in AAS sample after heating to and above $600{ }^{\circ} \mathrm{C}$ wüstite transforms to spinel.
\end{abstract}

Keywords: Amorphous materials, Porous materials, Sintering, Thermal properties, Steel slag, Alkali activated slag.

\section{Introduction}

*Corresponding author: E-mail: irena@ac.me ; Tel/Fax: ++382 20245406

(C) 2014. This manuscript version is made available under the Elsevier user license http://www.elsevier.com/open-access/userlicense/1.0/ 
EAFS is non-hazardous solid waste generated during the iron and steel scrap remelting in electric arc furnaces. Growing global steel demand and increasing share of steel production in electric arc furnaces impose the necessity of finding the appropriate route for EAFS valorization. Currently, this slag is considered as a possible additive in the production of asphalt mixtures [1], or for conventional concrete production $[2,3]$. Moreover, the silica and alumina content renders the EAFS an attractive source material for the alkaline activation process. This process involves a chemical reaction between oxides of silicon, aluminium and highly alkaline activator yielding a new material with amorphous or semi-amorphous structure, called alkali activated cement [4]. This reaction product of slag alkaline activation is a calcium silicate hydrate (C-S-H) gel, which is similar to the reaction product of the cement hydration process. It is highly amorphous and characterized by a high degree of aluminum substitution for silicon [5] which results in the formation of calcium (alumino) silicate hydrate $(\mathrm{C}-(\mathrm{A})-\mathrm{S}-\mathrm{H})$ gel [6]. This is the main difference between the reaction products of the cement hydration process and the alkaline activation of slag. The structure of $\mathrm{C}-(\mathrm{A})-\mathrm{S}-\mathrm{H}$ gel is strongly dependent on the type of alkali activator, which greatly affects the properties of AAS [7].

The understanding of the AAS behavior, when exposed to an aggressive environment, is critical in the prediction of the material life time and itsbehavior during exploitation. Hence, the aim of this paper was to investigate the AASperformances at high temperatures..

\section{Experiments}

The EAFS used in this investigation was supplied from the Steel Mill Nikšić in Montenegro. The mean particle size of the grinded slag was $d_{50}=24 \mu \mathrm{m}$ and its chemical composition in terms of main oxides was: $46.5 \% \mathrm{CaO} ; 23.5 \% \mathrm{FeO} ; 12.2 \mathrm{SiO}_{2} ; 6.5 \% \mathrm{MgO} ; 7.24 \% \mathrm{Al}_{2} \mathrm{O}_{3}$. The slag was alkali activated at solid to liquid mass ratio of 4 . The alkali activator was prepared by mixing sodium water glass (molar ratio $\mathrm{SiO}_{2} / \mathrm{Na}_{2} \mathrm{O}=3.2$ ) and $10 \mathrm{M} \mathrm{NaOH}$ solution, in the mass ratio of 2 . The obtained paste was cast in a cylindrical plastic mould, oven cured for $48 \mathrm{~h}$ at $65^{\circ} \mathrm{C}$. After demoulding, the samples were cured an additional 14 days at ambient temperature.

Subsequently, the AAS was subjected to heating at 600,800 and $1000{ }^{\circ} \mathrm{C}$. As soon as the target temperature was attained, it was maintained for an additional $60 \mathrm{~min}$ before the furnace was shut down to 
allow the specimens in the furnace to cool down to room temperature.All samples (including control samples) were tested for compressive strength using a universal testing machine according to MEST EN 1354:2011 standard and subjected to porosity investigations using an ASAP 2020 instrument. A pressure transducer in the range of $0-1000 \mathrm{~mm} \mathrm{Hg}( \pm 0.15 \%$ accuracy $)$ was used to monitor the vapor pressure in the system. . X-ray diffraction (XRD) patterns of EAFS and AAS were obtained on a Philips PW 1710 diffractometer using monochromatized $\mathrm{CuK} \alpha$ radiation $\left(\lambda=1.54178 \AA\right.$ ) and step-scan mode ( $2 \theta$ range was from 4 to $90^{\circ} 2 \theta$, step $0.02^{\circ} 2 \theta$, time $0.8 \mathrm{~s}$ ). Scanning electron microscopy (SEM) analysis of AAS was examined using a FEI 235 DB focused ion beam system, equipped with the EDAX (Energy-dispersive X-ray spectroscopy)energy dispersive spectrometer (EDS). TG/DTA measurements were performed in air atmosfere using a TA-SDT 2060 instrument. Approximately $20 \mathrm{mg}$ of the sample was crushed and placed in a platinum crucible and heated to $1200^{\circ} \mathrm{C}$ at a constant heating rate of $15^{\circ} \mathrm{C} / \mathrm{min}$.

\section{Results and discussion}

Microstructure of the AAS shown in Fig.1a is characterized by the presence of unreacted slag particles (denoted by A) partially covered and bonded in the reaction product of the alkaline activation of slag (denoted by B). The EDAX findings of B region (Fig. 1b) reveal the presence of $\mathrm{C}-(\mathrm{A})-\mathrm{S}-\mathrm{H}$ phase as a main reaction product of alkaline activation because of the high $\mathrm{Si}$ and $\mathrm{Ca}$ content and much lower $\mathrm{Al}$ content, [8]. Moreover, the low $\mathrm{Ca} / \mathrm{Si}$ ratio of 0.97, typical for AAS, was observed [7]. 


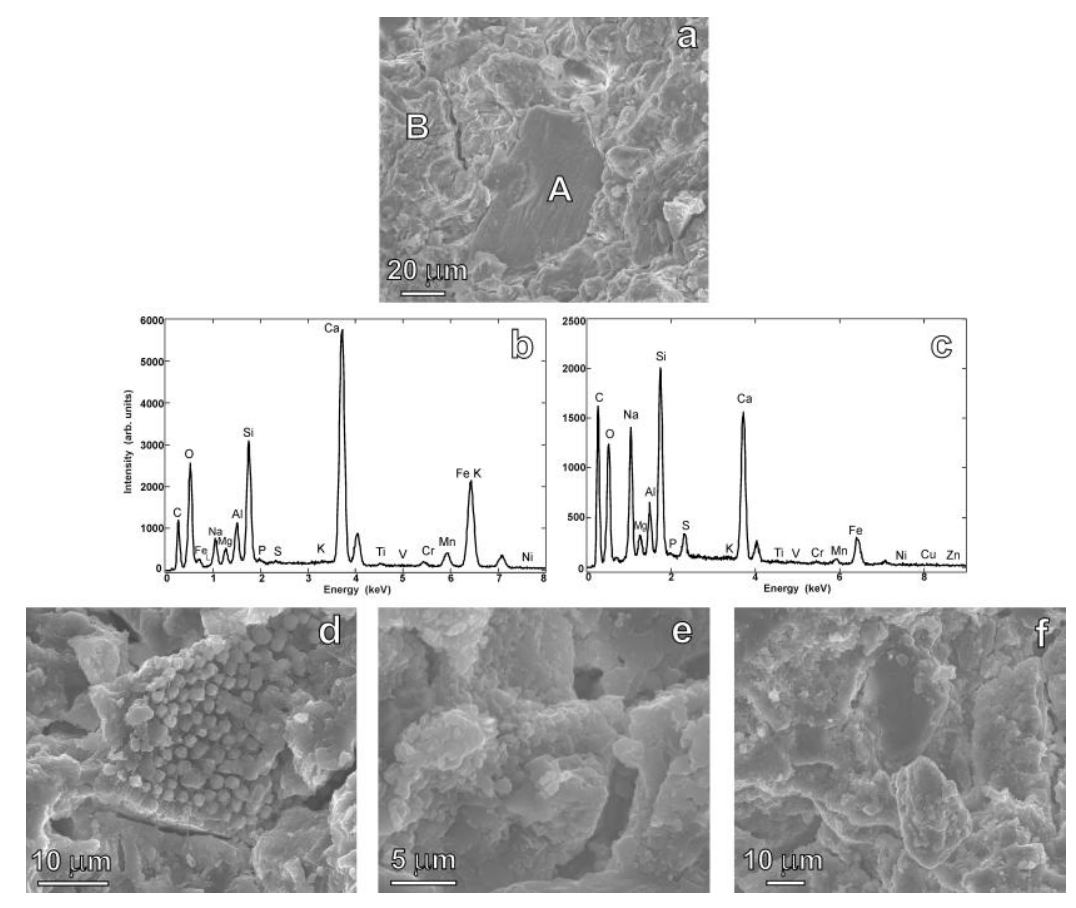

Fig.1. SEM-EDS of AAS (a,b,c) before and (d,e,fafter anealing. 

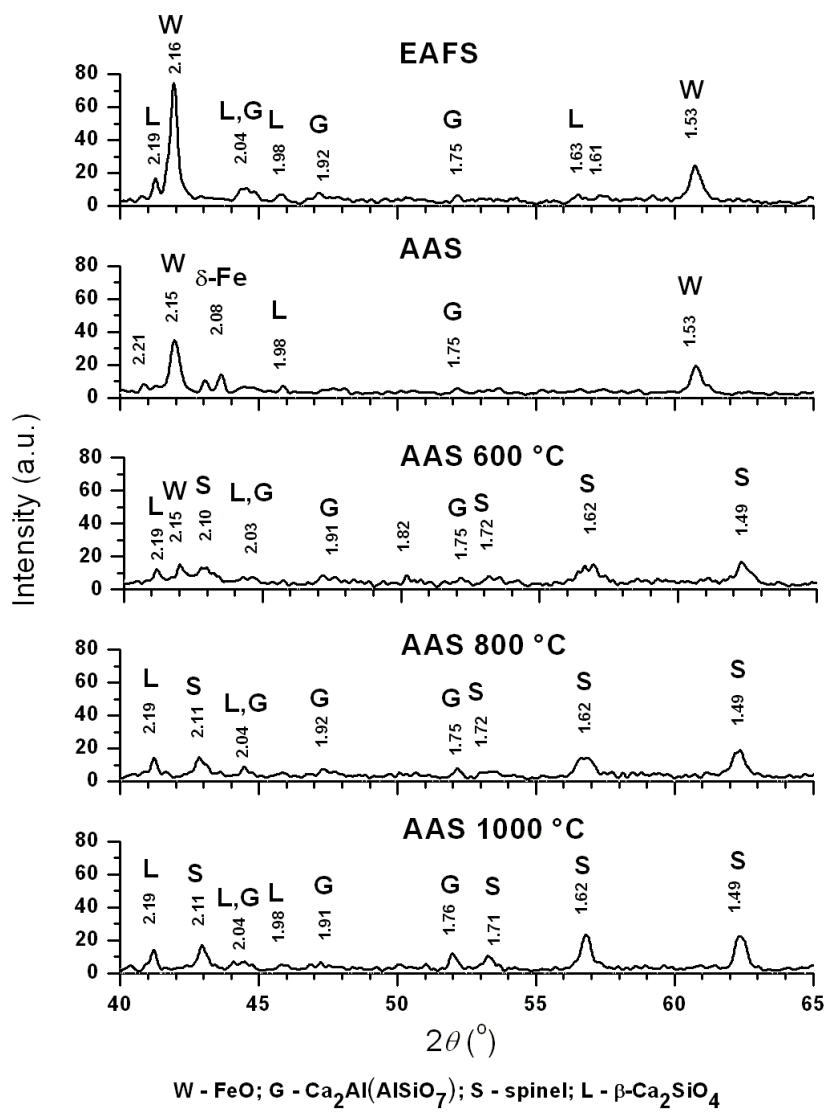

Fig. 2. XRD patterns of EAFS and AAS before and after annealing.

The results of XRD analysis (Fig. 2) have shown that EAFS and AAS before annealing are similar and mainly $\mathrm{X}$-ray amorphous. The main crystal phase is wüstite $\left(\mathrm{Fe}_{1-\mathrm{x}} \mathrm{O}\right)$, followed by larnit, $\beta-\mathrm{Ca}_{2} \mathrm{SiO}_{4}$, and gehlenite, $\mathrm{Ca}_{2} \mathrm{Al}\left(\mathrm{AlSiO}_{7}\right)$,. There is a possibility that small amounts of iron in AAS, but because it is a very small amount its unambiguous identification based on XRD measurements was not possible.In the thermally treated sample, besides larnite and gehlenite, a new spinel phase can be observed, suggesting that wüstite, $\mathrm{Fe}_{1-\mathrm{x}} \mathrm{O}_{4}$, was transformed to magnetite, $\mathrm{Fe}_{3} \mathrm{O}_{4}$, during thermal treatment.

The results of thermal analysis are shown in Fig.3. The TGA/DTA curves of EAFS indicate that above $600{ }^{\circ} \mathrm{C}$ phase transformation of wüstite into magnetite occurs, which is accompanied by mass increase and appearance of an endothermic peak on the DTA curve (Fig. 3a). The mass increase is attributed to the oxidation of $\mathrm{Fe}$ (II) to $\mathrm{Fe}(\mathrm{III})$ during the heating in air atmosfere. AAS shows typical thermal behavior for alkali activated materials upon heating (Fig. 3b). The sharp initial drop in mass, observed during heating up to 
$100{ }^{\circ} \mathrm{C}$, on the TG curve and an endothermic peak on the DTA curve, caused by the loss of adsorbed water, were observed [9]. With further heating, up to $400{ }^{\circ} \mathrm{C}$, mass continues to decrease due to further sample thermal dehydration. Mass loss between $400{ }^{\circ} \mathrm{C}$ and $600{ }^{\circ} \mathrm{C}$ is attributed to dehydration of the $\mathrm{C}-(\mathrm{A})-\mathrm{S}-\mathrm{H}$ phase, [10].

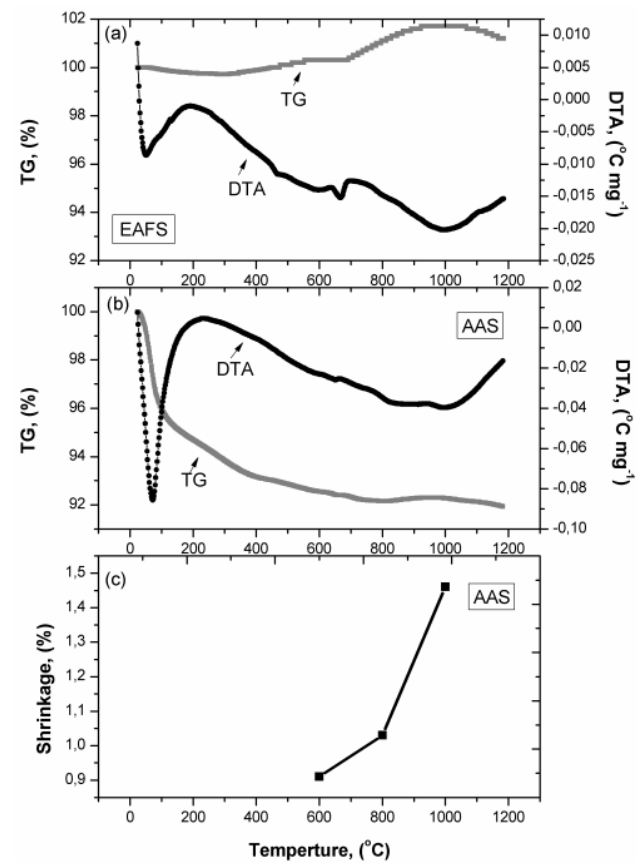

Fig. 3. TG/DTA thermograms of (a) EAFS, (b) AAS and (c) shrinkage of AAS.

Above $600^{\circ} \mathrm{C}$ there was a small change in mass and the sintering of alkali activated materials is taking place, as shown in the electron micrographs in Fig 1 (b, c and d). Sintering is accompanied by the volumetric shrinkage of samples (Fig. 3c) due to the interparticle space collapsing in the reaction product of alkaline activation [11], influencing the change of pore size

The strengthening of AAS at elevated temperatures correlates very well with the change in porosity (Table 1). After heating, the cumulative pore volume of AAS sample had a significant reduction compared to the initial pore volume. Generally, the thermal treatment of AAS influences the pore structure. Before annealing at elevated temperatures two close narrow regions on the differential curve of pore size distribution 
(PSD) for the AAS sample were observed (Fig. 4). The first region is characterized by the maximum which shows the width of most of the pores, around $3.3 \mathrm{~nm}$ and the second region shows the width of around $5.2 \mathrm{~nm}$. After annealing of AAS sample at $600^{\circ} \mathrm{C}$, the PSD curve still indicates the bimodal pore size distribution: the two peaks reflecting the two different pore systems, smaller (around $19.8 \mathrm{~nm}$ ) and the larger pore size (around $60.5 \mathrm{~nm}$ ). It is evident that exposure of AAS to $600^{\circ} \mathrm{C}$ shifts the pore size peak to a higher value and also leads to the development of a macropore system (with pore sizes exceeding $50 \mathrm{~nm}$ ). Development of large pores during annealing can probably be attributed to the coalescence of small pores into larger ones due to the release of evaporable water and dehydration of the reaction product of alkaline activation [12].

Although thermal treatment of AAS leads to the development of larger pore systems, the cumulative pore volume of AAS sample after heating to $600^{\circ} \mathrm{C}$ was significantly lower in comparison to the initial pore volume (Table 1). This is in agreement with the strength development after the thermal treatment. After being exposed to $800^{\circ} \mathrm{C}$, the curve of PSD was characterized by the two mesopore systems: smaller, around 20.6 $\mathrm{nm}$, larger, around $37.1 \mathrm{~nm}$ and by a third peak of around $76.2 \mathrm{~nm}$. Although the increase of temperature of heating leads to the development of larger pores, the continual decrease of cumulative pore volume and strength development of AAS samples were observed. Further increase of temperature of thermal treatment to $1000{ }^{\circ} \mathrm{C}$ eliminates the presence of macropores, and two mesopore systems of around $11.5 \mathrm{~nm}$ and $26.6 \mathrm{~nm}$ were observed with continual decrease of pore volume and strength development.

\section{Table 1}

Influence of annealing on the compressive strength and porosity of AAS.

\begin{tabular}{ccc}
\hline $\begin{array}{c}\text { Temperature, } \\
{ }^{\circ} \mathrm{C}\end{array}$ & $\begin{array}{c}\text { Cumulative pore } \\
\text { volume }, \mathrm{cm}^{3} / \mathrm{g}\end{array}$ & $\begin{array}{c}\text { Compressive strength, } \\
\mathrm{MPa}\end{array}$ \\
\hline untreated & 0.01419 & 38.80 \\
600 & 0.00714 & 44.32 \\
800 & 0.00232 & 42.43 \\
1000 & 0.00158 & 51.05 \\
\hline
\end{tabular}



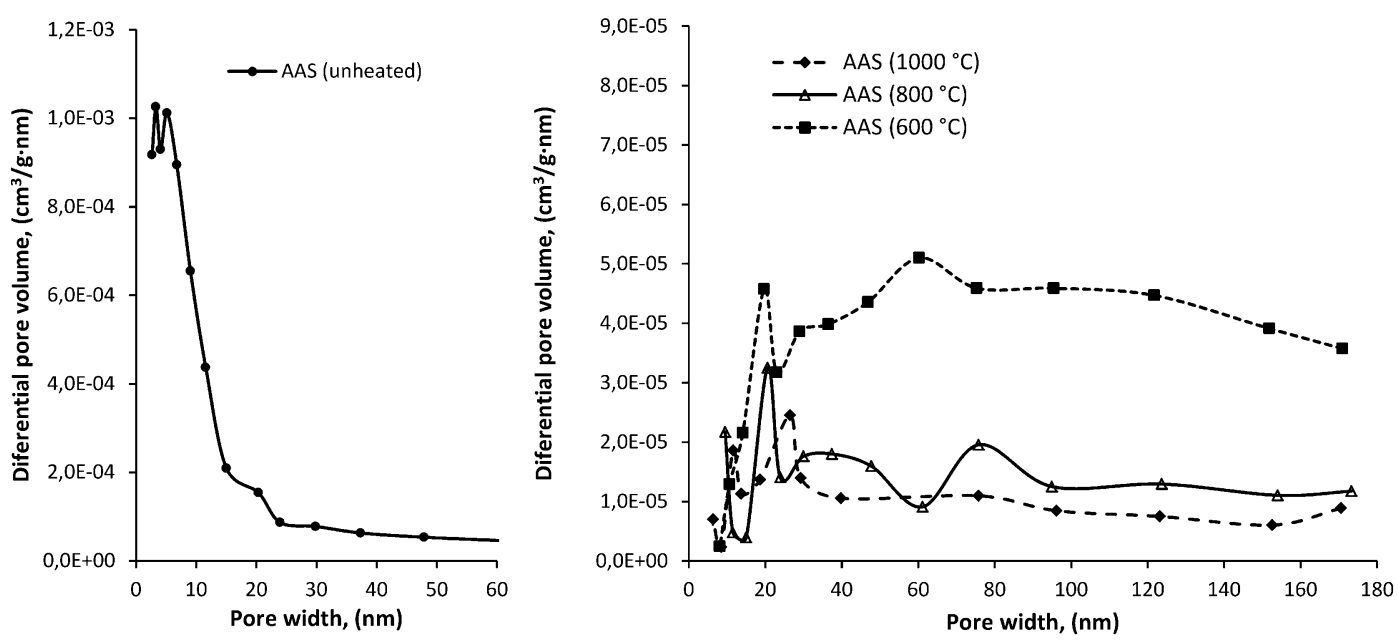

Fig. 4. Pore size distribution in the AAS before and after annealing.

\section{Conclusions}

The alkali activated slag (AAS) sample undergoes a series of modifications when it is exposed to thermal treatment in the range from $600^{\circ} \mathrm{C}$ to $1000^{\circ} \mathrm{C}$. The AAS sample exhibits improved strength at elevated temperatures. This strength increase is associated with the sintering process accompanied by a decrease in porosity. In addition, the heating of AAS sample to and above $600^{\circ} \mathrm{C}$ leads to the phase transformation of wüstite into magnetite.

\section{Acknowledgements}

The authors would like to acknowledge the financial support of the Montenegrin Ministry of Science in the framework of project No 01-460. VRR and VVR acknowledge supports from the Ministry of Education and Science of the Republic of Serbia, projects No. 172054 and No. 45019. SEM-EDS analysis were performed at the National Center for Electron Microscopy, Lawrence Berkeley National Laboratory, funded by the U.S. Department of Energy under Contract DE-AC02-05CH11231.

\section{References}

[1] Wu S, Xue Y, Ye Q, Chen Y. Utilization of steel slag as aggregates for stone mastic asphalt (SMA) mixtures. Build Environ 2007;42:2580-2585. 
[2] Pellegrino C, Cavagnis P, Faleschini F, Brunelli K, Properties of concretes with Black/Oxidizing Electric Arc Furnace slag aggregate, Cement Concret Comp 2013;37:232-240.

[3] Pellegrino C, Gaddo V. Mechanical and durability characteristics of concrete containing EAF slag as aggregate. Cement Concret Comp 2009;31:663-671.

[4] Davidovits J. Geopolymers, inorganic polymeric new materials. J Therm Anal 1991;37:1633-1656.

[5] Chen W, Brouwers HJH. The hydration of slag, part 1: reaction models for alkali-activated slag. J Mater Sci 2007;42:428-443.

[6] Arbi K, Palomo A,Fernández-Jiménez A. Alkali-activated blends of calcium aluminate cement and slag/diatomite. Ceram Int 2013;39:9237-9245.

[7] Puertas F, Palacios M, Manzano H, Dolado JS, Rico A, Rodríguez J. A model for the C-A-S-H gel formed in alkali-activated slag cements. J Eur Cera Soc 2011;31:2043-2056.

[8] Yip CK, Lukey GC. van Deventer JSJ. The coexistence of geopolymeric gel and calcium silicate hydrate at the early stage of alkaline activation. Cement Concret Res 2005;35:1688-1697.

[9] Ben Haha M, Le Saout G, Winnefeld F, Lothenbach B. Influence of activator type on hydration kinetics, hydrate assemblage and microstructural development of alkali activated blast-furnace slags. Cement Concret Res 2011;41:301-310.

[10] Bernal SA, Provis JL, Walkley B, Nicolas RS, Gehman JD, Brice DG, et al. Gel nanostructure in alkaliactivated binders based on slag andfly ash, and effects of accelerated carbonation. Cement Concret Res 2013;53:127-144.

[11] Bernal SA, Rodríguez ED, de Gutiérrez RB, Gordillo M, Provis JL, Mechanical and thermal characterisation of geopolymers based on silicate-activated metakaolin/slag blends. J Mater Sci 2011;46:5477-5486.

[12] Bakharev T. Thermal behavior of geopolymers prepared using class F fly ash and elevated temperature curing. Cement Concret Res 2006;36:1134-1147.

\section{Figure captions}

Fig.1. SEM-EDAX of AAS (a,b,c) before and (d,e,f) after anealing. 
Fig. 2. XRD patterns of EAFS and AAS before and after annealing.

Fig. 3. TG/DTA thermograms of (a) EAFS, (b) AAS and (c) shrinkage of AAS.

Fig. 4. Pore size distribution in the AAS before and after annealing. 